\title{
Biosynthesis and Biological Actions of Pineal Neurosteroids in Domestic Birds
}

\author{
Kazuyoshi Tsutsui $^{a}$ Shogo Haraguchi ${ }^{a}$ Megumi Hatori ${ }^{b, c}$ Tsuyoshi Hirota ${ }^{b, d}$ \\ Yoshitaka Fukadab \\ ${ }^{a}$ Department of Biology and Center for Medical Life Science, Waseda University, Tokyo, ${ }^{b}$ Department of Biophysics \\ and Biochemistry, Graduate School of Science, The University of Tokyo, Tokyo, Japan; 'Salk Institute for Biological \\ Studies, La Jolla and d Division of Biological Sciences and Center for Chronobiology, University of California San \\ Diego, La Jolla, Calif., USA
}

\section{Key Words}

Neurosteroids · 7a-Hydroxypregnenolone .

Allopregnanolone $\cdot$ Locomotor activity $\cdot$ Neuroprotection .

Purkinje cell · Brain · Pineal gland

\begin{abstract}
The central and peripheral nervous systems have the capacity of synthesizing steroids de novo from cholesterol, the socalled 'neurosteroids'. De novo synthesis of neurosteroids from cholesterol appears to be a conserved property across the subphylum vertebrata. Until recently, it was generally believed that neurosteroids are produced in neurons and glial cells in the central and peripheral nervous systems. However, our recent studies on birds have demonstrated that the pineal gland, an endocrine organ located close to the brain, is an important site of production of neurosteroids de novo from cholesterol. 7a-Hydroxypregnenolone is a major pineal neurosteroid that stimulates locomotor activity of juvenile birds, connecting light-induced gene expression with locomotion. The other major pineal neurosteroid allopregnanolone is involved in Purkinje cell survival by suppressing the activity of caspase-3, a crucial mediator of apoptosis during cerebellar development. This review is an updated summary of the biosynthesis and biological actions of pineal neurosteroids.

Copyright $\odot 2013$ S. Karger AG, Basel
\end{abstract}

The brain has traditionally been considered as a target site for peripheral steroid hormones in vertebrates. However, studies conducted over the past two decades have demonstrated that the central and peripheral nervous systems have the capacity of synthesizing steroids, the socalled 'neurosteroids' [for reviews, see 1-9]. De novo formation of neurosteroids in the brain was originally demonstrated in mammals [10-18], and subsequently in birds [2, 6, 19-35], amphibians [36-47] and fish [48-51]. Therefore, de novo synthesis of neurosteroids from cholesterol in the brain appears to be conserved across the subphylum vertebrata [1-9].

Until recently, it was generally accepted that neurosteroids are produced in neurons and glial cells in the central and peripheral nervous systems [for reviews, see 1-9]. However, there is now new evidence that, in the juvenile birds, the pineal gland, an endocrine organ located close to the brain, actively produces a variety of neurosteroids de novo from cholesterol [52, 53]. Notably, $7 a$-hydroxypregnenolone and allopregnanolone $(3 \alpha, 5 \alpha-$ tetrahydroprogesterone; $3 \alpha, 5 \alpha$-THP) are major neurosteroids secreted by the pineal gland $[52,53]$. Importantly, the pineal gland produces $7 \alpha$-hydroxypregnenolone stimulating locomotor activity in light- and circadian time-dependent manners [52]. On the other hand, allopregnanolone produced in the pineal gland prevents cell

\section{KARGER}

E-Mail karger@karger.com

www.karger.com/nen (c) 2013 S. Karger AG, Basel

0028-3835/13/0982-0097\$38.00/0
Prof. Kazuyoshi Tsutsui, $\mathrm{PhD}$

Laboratory of Integrative Brain Sciences, Department of Biology, Waseda University Center for Medical Life Science of Waseda University

2-2 Wakamatsu-cho, Shinjuku-ku, Tokyo 162-8480 (Japan)

E-Mail k-tsutsui@waseda.jp 
death of Purkinje cells by suppressing the activity of caspase- 3 in the cerebellum during development [53]. Based on these new findings, this review highlights the biosynthesis and biological actions of pineal neurosteroids.

\section{Studies on Neurosteroidogenesis in Birds}

Birds have served as excellent animal models for the investigation of neurosteroidogenesis in the brain. It has been demonstrated that the brain of the Japanese quail possesses cytochrome P450 side-chain cleavage enzyme (P450scc; gene name Cyp11a), 3 $\beta$-hydroxysteroid dehydrogenase $/ \Delta^{5}-\Delta^{4}$-isomerase ( $3 \beta$-HSD; gene name $H s d 3 b$ ), $5 \beta$-reductase (gene name $S r d 5 b$ ), cytochrome P450 17ahydroxylase/c17,20-lyase ( $\mathrm{P}_{450}$ 17a,lyase; gene name Cyp17), $17 \beta$-hydroxysteroid dehydrogenase (17 $\beta$-HSD; gene name $H s d 17 b)$, etc., and produces pregnenolone, progesterone, epipregnanolone ( $3 \beta, 5 \beta$-tetrahydroprogesterone; $3 \beta, 5 \beta$-THP), androstenedione, testosterone, and estradiol$17 \beta$ from cholesterol $[2,6,19-25]$. The expression and activity of cytochrome P450 aromatase (P450arom; gene name Cyp19), which converts testosterone into estradiol$17 \beta$, have also been demonstrated in the quail brain [5465]. Independently, neurosteroidogenesis in the brain has been demonstrated in the zebra finch [27-35]. The formation and metabolism of neurosteroids from cholesterol is now known to occur in the brain of various birds. Currently, studies on avian neurosteroids are an area of great interest to many researchers.

Recently, 7a-hydroxypregnenolone has been identified as a novel bioactive neurosteroid in the brain of the Japanese quail [66]. Importantly, 7a-hydroxypregnenolone acts on brain tissue as a novel neuronal modulator to stimulate locomotor activity of quail [66]. The presence of $7 a$-hydroxypregnenolone and a stimulatory action on locomotion were also demonstrated in the brain of the Japanese red-bellied newt [40]. Subsequently, it was found that cytochrome P450 7a-hydroxylase (cytochrome $\mathrm{P} 450_{7 \alpha}$; gene name Cyp7b) catalyzes the conversion of pregnenolone to $7 a$-hydroxypregnenolone in the brain of these species $[66,67]$. It was further demonstrated that melatonin acts on cytochrome $\mathrm{P}^{4} 50_{7 \alpha}$-expressing neurons to down-regulate $7 a$-hydroxypregnenolone synthesis, thus inducing diurnal locomotor changes in quail [66].

It is known that in birds and other vertebrates, the locomotor activity undergoes a circadian change [68] controlled by the diurnal rhythm of melatonin secretion [6974]. The discovery of the role of $7 a$-hydroxypregnenolone in mediating the action of melatonin on diurnal locomotor rhythmicity is an important step in understanding the molecular mechanism underlying melatonin regulation of the behavior [66]. A similar mechanism may be evident in other vertebrates [for reviews, see 75-79], because $7 a$-hydroxypregnenolone is also produced in the brain of newts [40] and mammals [80-83].

\section{Biosynthesis of Neurosteroids in the Pineal Gland}

\section{Neurosteroidogenesis in the Pineal Gland}

It was generally believed that neurosteroids are produced only in the central and peripheral nervous systems. However, recent studies carried out in chickens [52] and quail [53] have demonstrated that the pineal gland, an endocrine organ located close to the brain, actively synthesizes neurosteroids de novo from cholesterol via pregnenolone (fig. 1).

Pregnenolone is known to be the common precursor of all steroid hormones in vertebrates. The formation of pregnenolone is initiated by cleavage of the cholesterol side-chain by cytochrome $\mathrm{P} 450 \mathrm{scc}$, a rate-limiting mitochondrial enzyme originally found in peripheral steroidogenic glandular cells. Therefore, the demonstration of pregnenolone formation from cholesterol is essential to establish de novo neurosteroidogenesis in the pineal gland. As an initial step in the demonstration of pregnenolone biosynthesis in the pineal gland, we found that cytochrome P450scc is expressed in the pineal gland of juvenile chickens [52] and juvenile quail [53] by reverse transcription polymerase chain reaction (RT-PCR) analysis (fig. 1). Immunohistochemical labeling with cytochrome P450scc antibodies showed intense staining in cells forming follicular structures in the quail pineal gland [53]. Incubation of the pineal glands from quail chicks with tritiated cholesterol led to the formation of a radioactive metabolite that, upon high-performance liquid chromatography (HPLC) analysis, exhibited the same retention time as pregnenolone [53]. The occurrence of pregnenolone in the pineal gland was also demonstrated by gas chromatography-mass spectrometry (GC-MS) analysis [53].

Subsequently, the expressions of several key steroidogenic enzymes, including cytochrome $\mathrm{P} 450_{7 \alpha}, 3 \alpha-\mathrm{HSD}$, $3 \beta$-HSD, 5 $\alpha$-reductase, $5 \beta$-reductase, cytochrome $\mathrm{P} 450_{17 \alpha, \text { lyase, }} 17 \beta$-HSD and cytochrome P450arom have been demonstrated in the pineal gland of both juvenile chickens and juvenile quail $[52,53]$ by RT-PCR analyses (fig. 1). To clarify the biosynthetic pathways of neuros- 


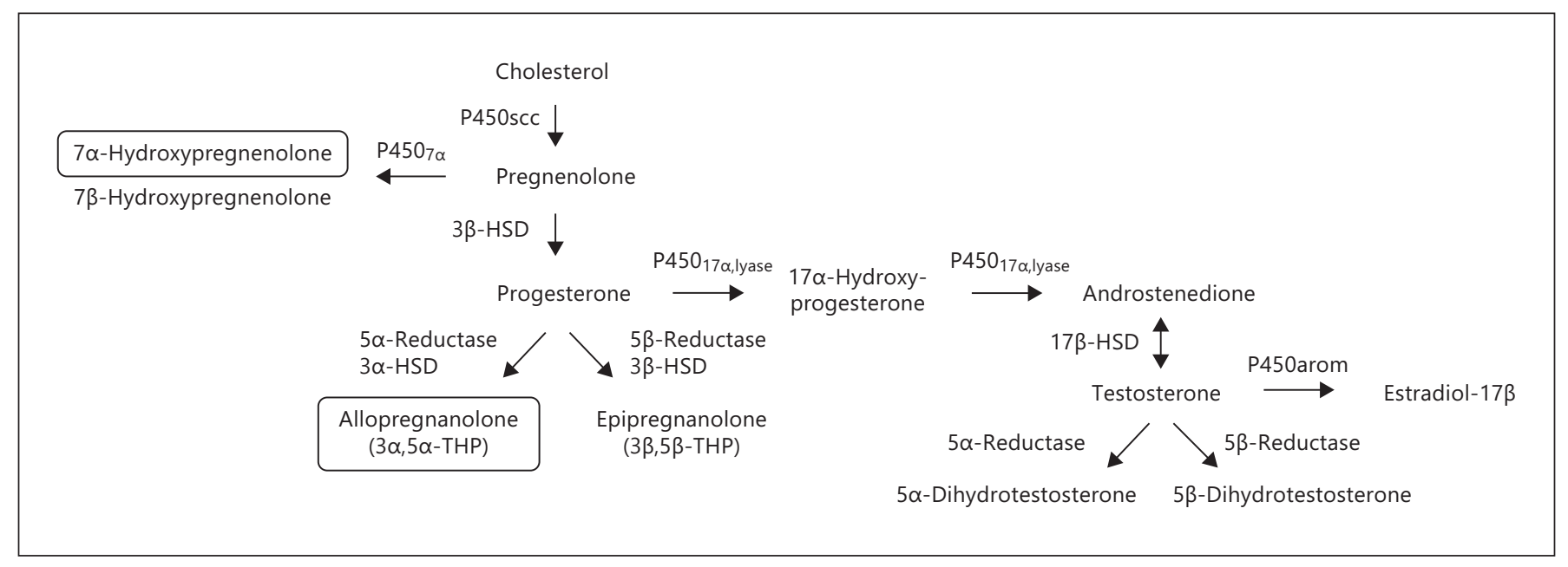

Fig. 1. Biosynthetic pathways for neurosteroids in the pineal gland. The arrows indicate the biosynthetic pathways of neurosteroids identified in the pineal glands of juvenile quail. The pineal gland actively produces a variety of neurosteroids de novo from cholesterol. $7 \alpha$-Hydroxypregnenolone and allopregnanolone are major products secreted by the pineal gland. P450scc, cytochrome
P450 side-chain cleavage enzyme; $\mathrm{P} 450_{7 \alpha}$, cytochrome P450 $7 \alpha$-hydroxylase; $3 \beta$-HSD, $3 \beta$-hydroxysteroid dehydrogenase $/ \Delta^{5}$ $\Delta^{4}$-isomerase; $3 \alpha$-HSD, $3 \alpha$-hydroxysteroid dehydrogenase $/ \Delta^{5}-\Delta^{4}$ isomerase; $\mathrm{P} 450_{17 \alpha, \text { lyase }}$, cytochrome $\mathrm{P} 450$ 17 $\alpha$-hydroxylase/c17,20lyase; $17 \beta$-HSD, $17 \beta$-hydroxysteroid dehydrogenase; P450arom, cytochrome P450 aromatase. For details, see text. teroids in the pineal gland, biochemical studies combined with HPLC and GC-MS analyses were further conducted. Pineal gland homogenates from quail chicks were incubated with tritiated pregnenolone, and subsequent analysis of the products by reversed-phase HPLC detected the formation of $7 \alpha$ - and/or $7 \beta$-hydroxypregnenolone [53] (fig. 1). In addition, progesterone, allopregnanolone and/or epipregnanolone, androstenedione, testosterone, $5 \alpha$ - and/or $5 \beta$-dihydrotestosterone and estradiol-17 $\beta$ were produced from the precursor pregnenolone [53] (fig. 1). Although isomers, such as $7 \alpha$ - and $7 \beta$-hydroxypregnenolone; allopregnanolone and epipregnanolone; and $5 \alpha$ - and $5 \beta$-dihydrotestosterone, were not separated from each other by HPLC analysis, the formation of these neurosteroids in the pineal gland was demonstrated by GC-MS analysis [53]. Derivatives of synthetic $7 \alpha-$ and $7 \beta$-hydroxypregnenolone, progesterone, allopregnanolone, epipregnanolone, androstenedione, testosterone, $5 \alpha$ - and $5 \beta$-dihydrotestosterone, estradiol- $17 \beta$, and the purified nonradioactive steroids produced by the pineal gland were applied to GC-selected ion monitoring (SIM) analysis, which showed the same mass spectral characteristics: $m / z 386$ for $7 \alpha$ - and $7 \beta$-hydroxypregnenolone, $m / z$ 510 for progesterone, $m / z 514$ for allopregnanolone and epipregnanolone, $\mathrm{m} / \mathrm{z} 482$ for androstenedione, $\mathrm{m} / \mathrm{z} 680$ for testosterone, $m / z 486$ for $5 \alpha$ - and $5 \beta$-dihydrotestosterone, and $m / z 664$ for estradiol-17 [53]. Unlike HPLC analysis, GC-MS analysis was capable of separating several pairs of isomers: $7 \alpha$ - and $7 \beta$-hydroxypregnenolone; allopregnanolone and epipregnanolone; and $5 \alpha$ - and $5 \beta$-dihydrotestosterone [53]. As summarized in figure 1, the neurosteroids produced in the pineal gland were identified as $7 \alpha$ - and $7 \beta$-hydroxypregnenolone, progesterone, allopregnanolone, epipregnanolone, androstenedione, testosterone, $5 \alpha$ - and $5 \beta$-dihydrotestosterone, and estradiol-17 $\beta$ [53].

In this way, a series of experiments using molecular and biochemical techniques have demonstrated that the pineal gland produces a variety of neurosteroids from cholesterol via pregnenolone in the juvenile birds. This is the first observation of de novo neurosteroidogenesis in the pineal gland in any vertebrate class.

\section{Major Pineal Neurosteroids}

To quantify major neurosteroids synthesized and released in the pineal gland, the pineal glands from quail chicks were cultured in medium 199 with tritiated pregnenolone. HPLC analysis revealed that pregnenolone was converted primarily into $7 \alpha$ - and/or $7 \beta$-hydroxypregnenolone and allopregnanolone and/or epipregnanolone in the pineal gland [53]. Comparison of the production of these major neurosteroids by HPLC analysis and the expressions of their steroidogenic enzyme mRNAs by realtime PCR in the pineal gland revealed that the synthesis 
of $7 \alpha$ - and/or $7 \beta$-hydroxypregnenolone and the expression of $C y p 7 b$ mRNA occur in both sexes of adult and juvenile quails, while they are significantly higher in juveniles than in adults [53]. Allopregnanolone and/or epipregnanolone synthesis and $S r d 5 a$ mRNA expression were also higher in juveniles than in adults in both sexes [53].

Subsequently, the syntheses of these major neurosteroids and the expressions of their steroidogenic enzyme mRNAs in the pineal gland were compared with those of different brain regions. The synthesis of $7 \alpha-$ and/or $7 \beta$-hydroxypregnenolone and the expression of $C y p 7 b$ mRNA were higher in the pineal gland than in the cerebellum and diencephalon [53]. Allopregnanolone and/or epipregnanolone synthesis and $S r d 5 a$ mRNA expression were also higher in the pineal gland than in the cerebellum and diencephalon [53]. It appears that the pineal gland produces $7 \alpha$-and/or $7 \beta$-hydroxypregnenolone and allopregnanolone and/or epipregnanolone far more abundantly than other brain regions.

To investigate the release of neurosteroids from the pineal gland, the pineal glands of quail chicks were cultured in medium 199 and these major neurosteroids were analyzed by GC-MS. Significant amounts of $7 \alpha$-hydroxypregnenolone and allopregnanolone were found to be released from the pineal gland into the culture medium, unlike $7 \beta$-hydroxypregnenolone and epipregnanolone [53] (fig. 1). Accordingly, 7a-hydroxypregnenolone and allopregnanolone appear to be the major neurosteroids secreted from the pineal gland (fig. 1).

\section{Biological Actions of Pineal Neurosteroids in the Brain}

Biological Action of Pineal 7 $\alpha$-hydroxypregnenolone on Locomotor Activity

The avian pineal gland is intrinsically light-sensitive, owing to its expression of several opsins including pinopsin [84], red-sensitive cone pigment [85], melanop$\sin [86]$ and neuropsin [87]. A combination of these opsins confers light-sensitivity on the pineal function governing rhythmic and nighttime-specific production of melatonin [88]. Hence, the avian pineal gland has been widely used for studies on light-regulation of the circadian clock [88]. The comprehensive analysis of light-regulated genes in the chicken pineal gland led to an unexpected finding that the pineal gland actively produces 7a-hydroxypregnenolone [52] .

The circadian clock is the internal time-measuring system that controls daily rhythms of physiology and behav- ior even in the absence of external time cues. As an important feature of the circadian clock, it is entrained to the external day/night cycles, and therefore the phase of the circadian clock is adjusted by the changes of environmental conditions such as light, temperature, and food in a time-of-day-dependent manner [89]. For example, a light pulse given at early night and late night induce phase delay and advance, respectively, while the light at subjective day causes no significant phase shifting effect. Despite the importance of phase-dependent light response as seen in the conserved feature across species, its molecular mechanism still remains to be solved. The chick pineal gland has been considered as one of the best tissues to work on this issue [88]. The circadian clock genes, such as Per, Cry, Clock, and Bmal, are highly conserved between the chick and mouse, and the transcription- and translation-based feedback loop of the clock genes forms a core part of the circadian clock regulating rhythmic expression of a variety of genes. For example, expression of $A A N A T$ gene encoding the rate limiting enzyme of melatonin synthesis is regulated by CLOCK-BMAL1 through an $\mathrm{E}$ box element in the promoter [90]. Chicken pineal transcriptome analyses identified many rhythmic genes involved in a variety of physiological processes including melatonin synthesis $[91,92]$. Among the clock (-related) genes, E4bp4 encodes a basic leucine zipper transcription factor that represses Per 2 expression. E4bp4 expression in the chick pineal gland is induced by a light pulse given at early night that causes the phase delay $[93,94]$ (fig. 2). To approach the molecular mechanism of the light-dependent phase-shift of the circadian clock, GeneChip analysis was conducted in order to search for genes induced by a light pulse at different time points of the day in the chicken pineal gland. Dark-reared juvenile chicks were compared with those exposed to light given at three time points of the day; daytime, early night or late night. The comprehensive transcriptome analysis revealed that Insig-1 and HMG-CoA synthase genes show a light response pattern similar to that of E4bp4 that is strongly induced by a light pulse given at early night [52]. Insig-1 and HMG-CoA synthase genes are involved in cholesterol biosynthetic pathway and the targets of a transcription factor SREBP (sterol regulatory element-binding protein). Noticeably, the light pulse given at early night stimulated the formation of the active form of SREBP transcription factor and, consistently, induced a number of SREBP-target genes involved in cholesterol biosynthesis. In transcription reporter assays, SREBP activated the transcription from the chicken $E 4 b p 4$ promoter, indicating a novel role of SREBP in the photic input pathway of 
Fig. 2. Light-stimulated production of $7 a-$ hydroxypregnenolone in the pineal gland. A light pulse given at early night activates formation of the active form of SREBP, sterol regulatory element-binding protein, resulting in induction of a number of genes governing cholesterol biosynthesis as well as a clock gene E4bp4 [52]. E4BP4 is a transcription factor that regulates the circadian clock through repression of clock gene Per2 $[93,94]$. SREBP-mediated induction of a series of cholesterol biosynthetic genes would enhance cholesterol synthesis and lead to production of $7 a$-hydroxypregnenolone, a neurosteroid stimulating locomotion. For details, see text.

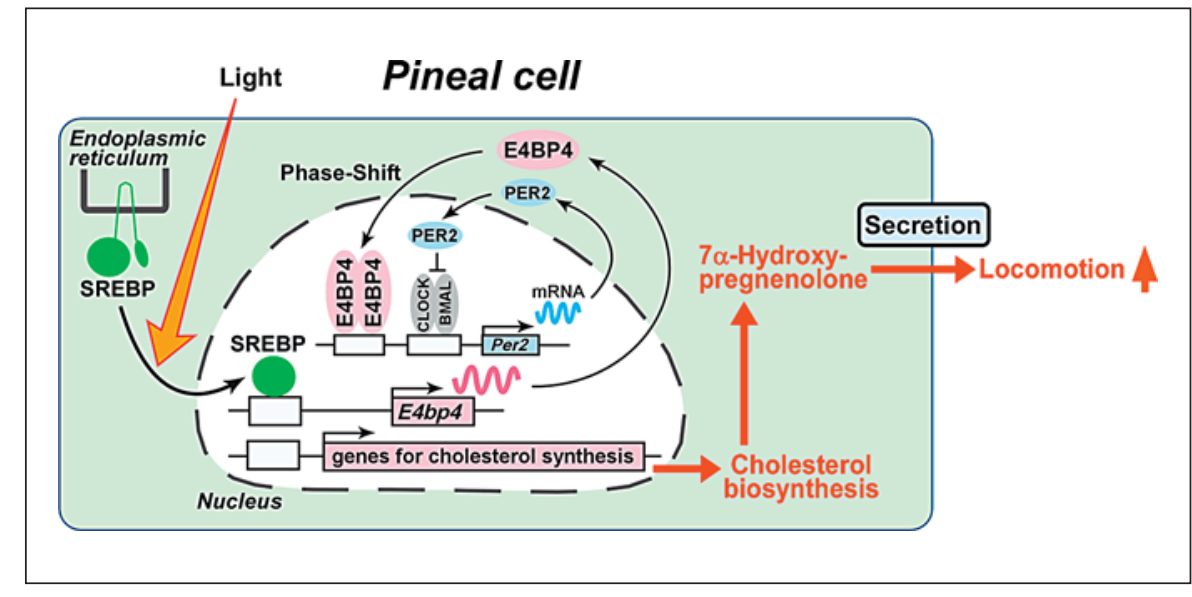

the circadian clock activated at early night (fig. 2). In contrast, the transcriptome analysis uncovered an activation of the heat shock and endoplasmic reticulum stress response pathways at late night [52], a potential connection of which with the core clock mechanism needs to be further characterized.

The photic induction of a series of SREBP-target genes involved in cholesterol biosynthesis raised the possibility that production of cholesterol (and its derivatives) may be up-regulated by light in the pineal gland. Based on the observations that StAR, P450scc, and $P 450_{7 \alpha}$ genes in the pineal gland are induced by light (see above) and that the locomotor activity is enhanced by 7a-hydroxypregnenolone in quail [66], neurosteroidogenesis in the chick pineal gland was investigated. Surprisingly, the chick pineal gland was found to have high activitiestoproduceandsecrete $7 \alpha$-hydroxypregnenolone [52] (fig. 2). In accordance with the transcriptional changes of cholesterol biosynthesis genes, a light pulse given at early night, but not at late night and daytime, activates $7 a$-hydroxypregnenolone production. Furthermore, the light exposure stimulates the locomotor activity of dark-reared juvenile chicks more strongly at early night than the other time points. Intriguingly, pinealectomy $(\mathrm{Px})$ reduces the light-dependent stimulation of the locomotor activity at early night. Collectively, the light activates the pineal production of 7a-hydroxypregnenolone in a time-of-day-dependent manner under the control of the circadian clock, and these properties may be essential for regulation of locomotor activity (fig. 2). The pineal gland appears to regulate sleep/wake cycles through dual hormonal signals: rhythmic production of melatonin and light-dependent production of $7 a$-hydroxypregnenolone.

New Developments in Pineal

Neurosteroids
Biological Action of Pineal Allopregnanolone on Purkinje Cell Survival

Because the two major pineal neurosteroids, $7 a$-hydroxypregnenolone and allopregnanolone, are abundantly released from the pineal gland of juvenile birds [53], not only pineal $7 a$-hydroxypregnenolone but also pineal allopregnanolone may play important roles in the brain of birds during development. In birds, the pineal gland is located near the cerebellum. The Purkinje cell is a principal cerebellar neuron that integrates the process of memory and learning. It has been reported that in birds and mammals Px induces cell loss in the brain including Purkinje cells during development [95, 96]. This observation suggests that allopregnanolone and/or 7a-hydroxypregnenolone secreted by the pineal gland may be involved in Purkinje cell survival during development.

To test this hypothesis, we conducted a series of experiments in the male juvenile quail. Px decreased the concentration of allopregnanolone in the cerebellum and induced apoptosis of Purkinje cells, whereas administration of allopregnanolone to Px quail chicks increased the concentration of allopregnanolone in the cerebellum and prevented apoptosis of Purkinje cells [ 53]. We further indicated that pineal allopregnanolone reaches the cerebellar Purkinje cells by diffusion shown by injection of ${ }^{3} \mathrm{H}$ allopregnanolone close to the pineal lumen [53] (fig. 3). Thus, allopregnanolone secreted by the pineal gland is considered to be an important factor for Purkinje cell survival during development (fig. 3). In contrast to allopregnanolone, administration of $7 a$-hydroxypregnenolone to Px quail chicks did not increase Purkinje cell survival [53]. Although 7a-hydroxypregnenolone did not facilitate Purkinje cell survival, this neurosteroid is involved in the reg- 


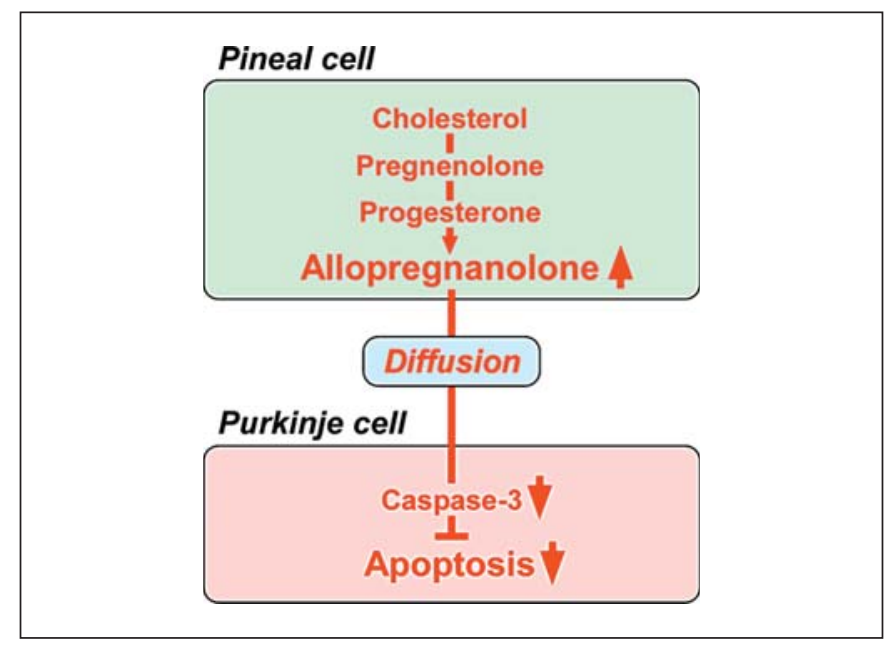

Fig. 3. Neuroprotective action of pineal allopregnanolone on Purkinje cell survival. Allopregnanolone is exceedingly produced in the pineal gland compared with other brain regions, and may affect the adjacent cerebellar Purkinje cells by diffusion, and saves Purkinje cells from apoptosis in the juvenile quail. Secreted pineal allopregnanolone inhibits the expression of active caspase- 3 that facilitates apoptosis of Purkinje cells in the cerebellum during development. For details, see text.

ulation of locomotion in birds $[52,66]$ as mentioned above.

The induction of cell loss of Purkinje cells in the cerebellum by Px suggests that certain other component(s) in the pineal gland may contribute to Purkinje cell survival during development. However, pineal melatonin did not facilitate Purkinje cell survival during development and did not affect cerebellar allopregnanolone synthesis and circulating allopregnanolone level in quail chicks [53]. It is therefore considered that pineal allopregnanolone but not melatonin acts as an important component of the pineal gland for Purkinje cell survival during development. We found that a significant amount of allopregnanolone is released from cultured pineal glands of juvenile quail [53]. This result suggests that pineal allopregnanolone reaches the target sites within the cerebellum by diffusion. Nevertheless, we cannot exclude the possibility of an anatomical link (e.g. blood vessels) from the pineal gland to the cerebellum.

Finally, we investigated the factor that mediates the neuroprotective effect of pineal allopregnanolone in Purkinje cells. It is well known that caspase-3 plays an important role in Purkinje cell death in vertebrates [97, 98]. Caspase-3 is a crucial mediator of apoptosis [97] in vertebrates including birds $[98,99]$. Interestingly, Px increased the number of Purkinje cells that expressed active cas- pase-3, a key protease in apoptotic pathway, in quail chicks and administration of allopregnanolone to Px quail chicks decreased the number of Purkinje cells expressing active caspase-3 [53]. These findings indicate that the neuroprotective effect of pineal allopregnanolone on Purkinje cells is associated with the decrease in caspase- 3 activity during development. Accordingly, pineal allopregnanolone exerts antiapoptotic effects in Purkinje cells by suppressing the activity of caspase-3 during development (fig. 3). This is a new function of the pineal gland for the prevention of Purkinje cell death in the developing cerebellum.

It is unclear whether the action of pineal allopregnanolone on caspase-3 activity in the Purkinje cell is rapid (i.e. mediated through a membrane receptor) or slow (i.e. involving transcriptional activation). On the other hand, the action of allopregnanolone produced in the brain is likely mediated through interaction with the $\mathrm{GABA}_{\mathrm{A}}$ receptor pathway, since allopregnanolone is a potent allosteric modulator of $\mathrm{GABA}_{\mathrm{A}}$ receptors $[100,101]$. However, the intracellular signaling pathway of pineal allopregnanolone suppressing the activity of caspase- 3 in the Purkinje cell remains unclear. Future studies are needed to clarify the intracellular signaling pathway of pineal allopregnanolone in the Purkinje cell.

\section{Conclusions and Future Directions}

It was generally accepted that the pineal gland, an endocrine organ located close to the brain, transduces photoperiodic changes to the neuroendocrine system by executing rhythmic secretion of melatonin. However, the formation of neurosteroids in the pineal gland was, until recently, unknown in vertebrates. Our recent studies provide new evidence that the pineal gland actively produces neurosteroids de novo from cholesterol. This is a paradigm shift of neurosteroid formation, because it was generally believed that neurosteroids are produced only in neurons and glial cells in the central and peripheral nervous systems. Importantly, $7 a$-hydroxypregnenolone is a major pineal neurosteroid that stimulates locomotor activity of juvenile birds, connecting light-induced gene expression with locomotion. The other major pineal neurosteroid allopregnanolone prevents cell death of Purkinje cells by suppressing the activity of caspase- 3 during cerebellar development. In birds, the syntheses of $7 a$-hydroxypregnenolone and allopregnanolone in the pineal gland are higher in juveniles than in adults, suggesting that these pineal neurosteroids may not be involved in the control of locomotor activity and Purkinje 
cell survival in adults. However, further studies are needed to determine physiological functions of these two major neurosteroids in adults. Unlike birds, it remains unclear whether the pineal gland of mammals produces neurosteroids including 7a-hydroxypregnenolone and allopregnanolone. Further studies are needed to demonstrate the biosynthesis and biological actions of pineal neurosteroids in mammals. These are new functions of the pineal gland by the actions of pineal neurosteroids.

\section{Acknowledgements}

This work was supported by Grants-in-Aid for Scientific Research from the Ministry of Education, Science and Culture, Japan (22132004 and 22227002 to KT and 24227001 to YF). We are grateful to the following collaborators, Masahiro Matsunaga, Saori Suzuki, Sakurako Hara, Masayuki Kusaka, Yuko Suzuki and Hubert Vaudry.

\section{Grant Support}

Grants-in-Aid for Scientific Research from the Ministry of Education, Science and Culture, Japan (22132004 and 22227002 to KT and 24227001 to YF).

\section{Disclosure Statement}

The authors have nothing to disclose.

\section{References}

$\checkmark 1$ Baulieu EE: Review: Neurosteroids: of the nervous system, by the nervous system, for the nervous system. Recent Prog Horm Res 1997;52:1-32.

-2 Tsutsui K, Ukena K, Takase M, Kohchi C, Lea RW: Review: Neurosteroid biosynthesis in vertebrate brains. Comp Biochem Physiol C 1999;124:121-129.

-3 Tsutsui K, Ukena K, Usui M, Sakamoto H, Takase M: Review: Novel brain function: biosynthesis and actions of neurosteroids in neurons. Neurosci Res 2000;36:261-273.

$\checkmark 4$ Compagnone NA, Mellon SH: Review: Neurosteroids: biosynthesis and function of these novel neuromodulators. Front Neuroendocrinol 2000;21:1-56.

5 Mellon SH, Vaudry H: Review: Biosynthesis of neurosteroids and regulation of their synthesis. Int Rev Neurobiol 2001;46:33-78.

-6 Tsutsui K, Matsunaga M, Ukena K: Review: Biosynthesis and biological actions of neurosteroids in the avian brain. Avian Poultry Biol Rev 2003;14:63-78.

7 Tsutsui K, Matsunaga M, Miyabara H, Ukena K: Review: Neurosteroid biosynthesis in the quail brain. J Exp Zool 2006;305A:733-742.

8 Tsutsui K, Mellon SH: Review: Neurosteroids in the brain neuron: Biosynthesis, action and medicinal impact on neurodegenerative disease. Central Nerv Syst Agents Med Chem 2006;6:73-82.

-9 Do-Rego JL, Seong JY, Burel D, Leprince J, Luu-The V, Tsutsui K, Tonon MC, Pelletier G, Vaudry H: Review: Neurosteroid biosynthesis: enzymatic pathways and neuroendocrine regulation by neurotransmitters and neuropeptides. Front Neuroendocrinol 2009; 30:259-301.

10 Corpéchot C, Robel P, Axelson M, Sjövall J, Baulieu EE: Characterization and measurement of dehydroepiandrosterone sulfate in rat brain. Proc Natl Acad Sci USA 1981;78: 4704-4707.

11 Corpéchot C, Synguelakis M, Talha S, Axelson M, Sjövall J, Vihko R, Baulieu EE, Robel $\mathrm{P}$ : Pregnenolone and its sulfate ester in rat brain. Brain Res 1983;270:119-125.

12 Robel P, Baulieu EE: Neuro-steroids, $3 \beta$-hydroxy- $\Delta^{5}$-derivatives in the rodent brain. Neurochem Int 1985;7:953-958.

13 Lanthier A, Patwardhan VV: Sex steroids and 5 -en-3 $\beta$-hydroxysteroids in specific regions of the human brain and cranial nerves. J Steroid Biochem 1986;25:445-449.

14 Robel P, Bourreau E, Corpéchot C, Dang DC, Halberg F, Clarke C, Haug M, Schlegel ML, Synguelakis M, Vourch C, et al: Neuro-steroids: $3 \beta$-hydroxy- $\Delta 5$-derivatives in rat and monkey brain. J Steroid Biochem 1987;27:649-655.

15 Jo DH, Abdallah MA, Young J, Baulieu EE, Robel P: Pregnenolone, dehydroepiandrosterone, and their sulfate and fatty acid esters in the rat brain. Steroids 1989;54:287-297.

16 Mathur C, Prasad VV, Raju VS, Welch M, Lieberman S: Steroids and their conjugates in the mammalian brain. Proc Natl Acad Sci USA 1993;90:85-88.

17 Mellon SH, Deschepper CF: Neurosteroid biosynthesis: genes for adrenal steroidogenic enzymes are expressed in the brain. Brain Res 1993;629:283-292.

18 Compagnone NA, Bulfone A, Rubenstein JL, Mellon SH: Steroidogenic enzyme P450c17 is expressed in the embryonic central nervous system. Endocrinology 1995;136:5212-5223.

19 Matsunaga M, Ukena K, Tsutsui K: Expression and localization of the cytochrome P450 17 -hydroxylase/c17,20-lyase in the avian brain. Brain Res 2001;899:112-122.

20 Matsunaga M, Ukena K, Tsutsui K: Androgen biosynthesis in the quail brain. Brain Res 2002;948:180-185.
21 Tsutsui K, Schlinger BA: Steroidogenesis in the avian brain; in Dawson A, Chaturvedi CM (eds): Avian endocrinology. Narosa Publishing House, New Delhi, 2001, pp 59-77.

22 Tsutsui K, Yamazaki T: Avian neurosteroids I. Pregnenolone biosynthesis in the quail brain. Brain Res 1995;678:1-9.

23 Tsutsui K, Yamazaki T, Usui M, Furukawa Y, Ukena K, Kohchi C, Kominami S: P450scc activity in the brain; in Harvey S, Etches RJ (eds): Perspectives in avian endocrinology. Journal of Endocrinol Ltd, Bristol, 1997, pp 427-436.

24 Ukena K, Honda Y, Inai Y, Kohchi C, Lea RW, Tsutsui K: Expression and activity of $3 \beta$-hydroxysteroid dehydrogenase $/ \Delta^{5}-\Delta^{4}$ isomerase in different regions of the avian brain. Brain Res 1999;818:536-542.

25 Ukena K, Honda Y, Lea RW, Tsutsui K: Developmental changes in progesterone biosynthesis and metabolism in the quail brain. Brain Res 2001;898:190-194.

26 Usui M, Yamazaki T, Kominami S, Tsutsui K: Avian neurosteroids. II. Localization of a cytochrome P450scc-like substance in the quail brain. Brain Res 1995;678:10-20.

27 Freking F, Nazairians T, Schlinger BA: The expression of the sex steroid-synthesizing enzymes CYP11A1, 3 $\beta-H S D, C Y P 17$, and CYP19 in gonads and adrenals of adult and developing zebra finches. Gen Comp Endocrinol 2000;119:140-151.

28 London S, Schlinger BA: Steroidogenic enzymes along the ventricular proliferative zone in the developing songbird brain. J Comp Neurol 2007;502:507-521.

29 London SE, Boulter J, Schlinger BA: Cloning of the zebra finch androgen synthetic enzyme CYP17: a study of its neural expression throughout posthatch development. J Comp Neurol 2003;467:496-508. 
- 30 London S, Monks DA, Wade J, Schlinger BA: Widespread capacity for steroid synthesis in the avian brain and song system. Endocrinology 2006; 147:5975-5987.

- 31 London SE, Itoh Y, Lance VA, Wise PM, Ekanayake PS, Oyama RK, Arnold AP, Schlinger BA: Neural expression and post-transcriptional dosage compensation of the steroid metabolic enzyme $17 \beta$-HSD type 4 . BMC Neuroscience 2010;11:47.

- 32 Schlinger BA, Lane NI, Grisham W, Thompson L: Androgen synthesis in a songbird: a study of cyp17 (17a-hydroxylase/c17,20-lyase) activity in the zebra finch. Gen Comp Endocrinol 1999;113:46-58.

- 33 Soma KK, Alday NA, Hau M, Schlinger BA: Dehydroepiandrosterone metabolism by $3 \beta$-hydroxysteroid dehydrogenase $/ \Delta^{5}-\Delta^{4}$ isomerase in adult zebra finch brain: sex difference and rapid effect of stress. Endocrinology 2004;145:1668-1677.

- 34 Tam H, Schlinger BA: Activities of $3 \beta$-HSD and aromatase in slices of developing and adult zebra finch brain. Gen Comp Endocrinol 2007;150:26-33.

- 35 Vanson A, Arnold AP, Schlinger BA: $3 \beta$-Hydroxysteroid dehydrogenase/isomerase and aromatase activity in primary cultures of developing zebra finch telencephalon: dehydroepiandrosterone as substrate for synthesis of androstenedione and estrogens. Gen Comp Endocrinol 1996;102:342-350.

- 36 Beaujean D, Mensah-Nyagan AG, Do-Rego JL, Luu-The V, Pelletier G, Vaudry H: Immunocytochemical localization and biological activity of hydroxysteroid sulfotransferase in the frog brain. J Neurochem 1999;72:848-857.

-37 Bruzzone F, Do-Rego JL, Luu-The V, Pelletier G, Vallarino M, Vaudry H: Immunohistochemical localization and biological activity of $3 \beta$-hydroxysteroid dehydrogenase and $5 a$-reductase in the brain of the frog, Rana esculenta, during development. J Chem Neuroanat 2010;39:35-50.

38 Do-Rego JL, Tremblay Y, Luu-The V, Repello E, Vallarino M, Belanger A, Pelletier G, Vaudry H: Immunocytochemical localization and biological activity of the steroidogenic enzyme cytochrome P450 17a-hydroxylase/ $\mathrm{C} 17,20$-lyase $\left(\mathrm{P} 40_{\mathrm{C} 17}\right)$ in the frog brain and pituitary. J Neurochem 2007;100:251-268.

- 39 Inai Y, Nagai K, Ukena K, Oishi T, Tsutsui K: Seasonal changes in neurosteroids in the urodele brain and environmental factors inducing their changes. Brain Res 2003;959:214-225.

40 Matsunaga M, Ukena K, Baulieu EE, Tsutsui $\mathrm{K}$ : 7a-Hydroxypregnenolone acts as a neuronal activator to stimulate locomotor activity of breeding newts by means of the dopaminergic system. Proc Natl Acad Sci USA 2004 101:17282-17287.

41 Mensah-Nyagan AG, Feuilloley M, Dupont E, Do-Rego JL, Leboulenger F, Pelletier G, Vaudry H: Immunocytochemical localization and biological activity of $3 \beta$-hydroxysteroid dehydrogenase in the central nervous system of the frog. J Neurosci 1994;14:7306-7318.
42 Mensah-Nyagan AG, Do-Rego JL, Feuilloley M, Marcual A, Lange C, Pelletier G, Vaudry H: In vivo and in vitro evidence for the biosynthesis of testosterone in the telencephalon of the female frog. J Neurochem 1996;67:413-422.

43 Mensah-Nyagan AG, Feuilloley M, Do-Rego JL, Marcual A, Lange C, Tonon MC, Pelletier G, Vaudry H: Localization of $17 \beta$-hydroxysteroid dehydrogenase and characterization of testosterone in the brain of the male frog. Proc Natl Acad Sci USA 1996;93:1423-1428.

44 Mensah-Nyagan AG, Do-Rego JL, Beaujean D, Luu-The V, Pelletier G, Vaudry H: Review: Neurosteroids: expression of steroidogenic enzymes and regulation of steroid biosynthesis in the central nervous system. Pharmacol Rev 1999;51:63-81.

45 Takase M, Ukena K, Yamazaki T, Kominami S, Tsutsui K: Pregnenolone, pregnenolone sulfate and cytochrome P450 side-chain cleavage enzyme in the amphibian brain and their seasonal changes. Endocrinology 1999; 140:1936-1944.

46 Takase M, Ukena K, Tsutsui K: Expression and localization of cytochrome P45011 $\beta$, aldo mRNA in the frog brain. Brain Res 2002;950: 288-296.

47 Takase M, Haraguchi S, Hasunuma I, Kikuyama S, Tsutsui K: Expression of cytochrome P450 side-chain cleavage enzyme mRNA in the brain of the Red-bellied newt Cynops pyrrhogaster. Gen Comp Endocrinol 2011;170:468-474.

48 Brion F, Le Page Y, Piccini B, Cardoso O, Tong SK, Chung BC, Kah O: Screening estrogenic activities of chemicals or mixtures in vivo using transgenic (cyp19a1b-GFP) zebrafish embryos. PLoS ONE 2012;7:e36069.

49 Diotel N, Do Rego JL, Anglade I, Vaillant C, Pellegrini E, Gueguen MM, Mironov S, Vaudry H, Kah O: Activity and expression of steroidogenic enzymes in the brain of adult zebrafish. Eur J Neurosci 2011;34:45-56.

50 Menuet A, Pellegrini E, Brion F, Gueguen MM, Anglade I, Pakdel F, Kah O: Expression and estrogen-dependent regulation of the zebrafish brain aromatase gene. J Comp Neurol 2005;485:304-320.

51 Sakamoto H, Ukena K, Tsutsui K: Activity and localization of $3 \beta$-hydroxysteroid dehydrogenase $/ \Delta^{5}-\Delta^{4}$-isomerase in the zebrafish central nervous system. J Comp Neurol 2001;439:291-305.

- 52 Hatori M, Hirota T, Iitsuka M, Kurabayashi N, Haraguchi S, Kokame K, Sato R, Nakai A, Miyata T, Tsutsui K, Fukada Y: Light-dependent and circadian clock-regulated activation of sterol regulatory element-binding protein, $\mathrm{X}$-box-binding protein 1 , and heat shock factor pathways. Proc Natl Acad Sci USA 2011; 108:4864-4869.

53 Haraguchi S, Hara S, Ubuka T, Mita M, Tsutsui K: Possible role of pineal allopregnanolone in Purkinje cell survival. Proc Natl Acad Sci USA 2012;109:21110-21115.

54 Schlinger BA, Callard GV: A comparison of aromatase, $5 \alpha$, and $5 \beta$-reductase activities in the brain and pituitary of male and female quail (Coturnix coturnix japonica). J Exp Zool 1987;242:171-180.

55 Schlinger BA, Callard GV: Aromatase activity in quail brain: Correlation with aggressiveness. Endocrinology 1989;124:437-443.

56 Schlinger BA, Callard GV: Localization of aromatase in synaptosomal and microsomal subfractions of quail (Coturnix coturnix japonica) brain. Neuroendocrinology 1989;49: 434-441.

57 Schlinger BA, Callard GV: Brain-steroid interactions and the control of aggressive behavior in birds; in MacLeod RM, Muller E (eds): Neuroendocrine Perspectives. Springer-Verlag, New York, 1991, pp 1-43.

58 Balthazart J, Foidart A, Harada N: Immunocytochemical localization of aromatase in the brain. Brain Res 1990;514:327-333.

59 Balthazart J, Foidart A, Surlemont C, Vockel A, Harada N: Distribution of aromatase in the brain of the Japanese quail, ring dove, and zebra finch: An immunocytochemical study. J Comp Neurol 1990;301:276-288.

60 Balthazart J, Foidart A, Surlemont C, Harada $\mathrm{N}$ : Neuroanatomical specificity in the co-localization of aromatase and estrogen receptors. J Neurobiol 1991;22:143-157.

61 Balthazart J, Baillien M, Ball GF: Rapid and reversible inhibition of brain aromatase activity. J Neuroendocrinol 2001;13:63-73.

62 Balthazart J, Baillien M, Ball GF: Phosphorylation processes mediate rapid changes of brain aromatase activity. J Steroid Biochem Mol Biol 2001;79:261-277.

63 Balthazart J, Baillien M, Charlier T, Ball G: Calcium-dependent phosphorylation processes control brain aromatase in quail. Eur J Neurosci 2003;171:591-606.

64 Balthazart J, Baillien M, Ball GF: Rapid control of brain aromatase activity by glutamatergic inputs. Endocrinology 2006;147:359366

65 Pradhan DS, Yu Y, Soma KK: Rapid estrogen regulation of DHEA metabolism in the male and female songbird brain. J Neurochem 2008; 104:244-253.

- 66 Tsutsui K, Inoue K, Miyabara H, Suzuki S, Ogura Y, Haraguchi S: 7 $\alpha$-Hydroxypregnenolone mediates melatonin action underlying diurnal locomotor rhythms. J Neurosci 2008; 28:2158-2167.

67 Haraguchi S, Koyama T, Hasunuma I, Vaudry $\mathrm{H}$, Tsutsui K: Prolactin increases the synthesis of $7 a$-hydroxypregnenolone, a key factor for induction of locomotor activity, in breeding male newts. Endocrinology 2010;151:22112222.

68 Saper CB, Lu J, Chou TC, Gooley J: The hypothalamic integrator for circadian rhythms. Trends Neurosci 2005;28:152-157.

69 Binkley S, Kluth E, Menaker M: Pineal function in sparrows: circadian rhythms and body temperature. Science 1971;174:311-314.

70 John TM, Itoh S, George JC: On the role of the pineal in thermoregulation in the pigeon. Horm Res 1978;9:41-56. 
71 Cassone VM, Menaker M: Is the avian circadian system a neuroendocrine loop? J Exp Zool 1984;232:539-549.

72 Chabot CC, Menaker M: Circadian feeding and locomotor rhythms in pigeons and house sparrows. J Biol Rhythms 1992;7:287-299.

73 Hau M, Gwinner E: Melatonin facilitates synchronization of sparrow circadian rhythms to light. J Comp Physiol A 1994;175:343-347.

74 Warren WS, Cassone VM: The pineal gland: photoreception and coupling of behavioral, metabolic, and cardiovascular circadian outputs. J Biol Rhythms 1995;10:64-79.

-75 Tsutsui K, Haraguchi S, Inoue K, Miyabara H, Suzuki S, Ogura Y, Koyama T, Matsunaga M, Vaudry H: Review: Identification, biosynthesis, and function of $7 \alpha$-hydroxypregnenolone, a new key neurosteroid controlling locomotor activity, in nonmammalian vertebrates. Ann NY Acad Sci 2009;1163:308-315.

-76 Tsutsui K, Inoue K, Miyabara H, Suzuki S, Ogura Y, Tobari Y, Haraguchi S: Review: Discovery of a novel avian neurosteroid, $7 \alpha$-hydroxypregnenolone, and its role in the regulation of the diurnal rhythm of locomotor activity in Japanese quail. Gen Comp Endocrinol 2009;163:117-122.

-77 Tsutsui K, Haraguchi S, Matsunaga M, Inoue K, Vaudry H: Review: 7a-hydroxypregnenolone, a new key regulator of locomotor activity of vertebrates: identification, mode of action, and functional significance. Front Endocrinol (Lausanne) 2010;1:article 9;1-13.

-78 Tsutsui K, Haraguchi S, Matsunaga M, Koyama T, Do-Rego JL, Vaudry H: Review: Identification of $7 a$-hydroxypregnenolone, a novel bioactive amphibian neurosteroid stimulating locomotor activity, and its physiological roles in the regulation of locomotion. Gen Comp Endocrinol 2010;168:275279.

-79 Tsutsui K, Haraguchi S, Matsunaga M, Koyama T, Do Rego JL, Vaudry H: Review: $7 a$-Hydroxypregnenolone, a new key regulator of amphibian locomotion: discovery, progress and prospect. Gen Comp Endocrinol 2012;176:440-447.

80 Akwa Y, Morfin RF, Robel P, Baulieu EE: Neurosteroid metabolism: 7a-Hydroxylation of dehydroepiandrosterone and pregnenolone by rat brain microsomes. Biochem J 1992;288:959-964.
81 Doostzadeh J, Morfin R: Effects of cytochrome P450 inhibitors and of steroid hormones on the formation of 7-hydroxylated metabolites of pregnenolone in mouse brain microsomes. J Endocrinol 1997;155:343-350.

82 Weill-Engerer S, David JP, Sazdovitch V, Liere P, Schumacher M, Delacourte A, Baulieu EE, Akwa Y: In vitro metabolism of dehydroepiandrosterone (DHEA) to $7 \alpha$-hydroxyDHEA and $\Delta^{5}$-androstene- $3 \beta, 17 \beta$-diol in specific regions of the aging brain from $\mathrm{Al}-$ zheimer's and non-demented patients. Brain Res 2003;969:117-125.

83 Yau JL, Rasmuson S, Andrew R, Graham M, Noble J, Olsson T, Fuchs E, Lathe R, Seckl JR: Dehydroepiandrosterone 7-hydroxylase CYP7B: predominant expression in primate hippocampus and reduced expression in Alzheimer's disease. Neuroscience 2003;121: 307-314.

84 Okano T, Yoshizawa T, Fukada Y: Pinopsin is a chicken pineal photoreceptive molecule. Nature 1994;372:94-97.

85 Okano T, Takanaka Y, Nakamura A, Hirunagi K, Adachi A, Ebihara S, Fukada Y: Immunocytochemical identification of pinopsin in pineal glands of chicken and pigeon. Brain Res Mol Brain Res 1997;50:190-196.

86 Chaurasia SS, Rollag MD, Jiang G, Hayes WP, Haque R, Natesan A, Zatz M, Tosini G, Liu C, Korf HW, Iuvone PM, Provencio I: Molecular cloning, localization and circadian expression of chicken melanopsin (Opn4): differential regulation of expression in pineal and retinal cell types. J Neurochem 2005;92: 158-170.

87 Yamashita T, Ohuchi H, Tomonari S, Ikeda $\mathrm{K}$, Sakai K, Shichida Y: Opn5 is a UV-sensitive bistable pigment that couples with Gi subtype of G protein. Proc Natl Acad Sci USA 2010; 107:22084-22089.

88 Fukada Y, Okano T: Review: Circadian clock system in the pineal gland. Mol Neurobiol 2002;25:19-30

89 Hirota T, Fukada Y: Review: Resetting mechanism of central and peripheral circadian clocks in mammals. Zool Sci 2004;21:359-368.
90 Chong NW, Bernard M, Klein DC: Characterization of the chicken serotonin $\mathrm{N}$-acetyltransferase gene. J Biol Chem 2000;275: 32991-32998.

-91 Karaganis SP, Kumar V, Beremand PD, Bailey MJ, Thomas TL, Cassone VM: Circadian genomics of the chick pineal gland in vitro. BMC Genomics 2008;9:206.

92 Bailey MJ, Beremand PD, Hammer R, BellPedersen D, Thomas TL, Cassone VM: Transcriptional profiling of the chick pineal gland, a photoreceptive circadian oscillator and pacemaker. Mol Endocrinol 2003;17: 2084-2095.

93 Doi M, Nakajima Y, Okano T, Fukada Y: Light-induced phase-delay of the chicken pineal circadian clock is associated with the induction of $c E 4 b p 4$, a potential transcriptional repressor of cPer2 gene. Proc Natl Acad Sci USA 2001;98:8089-8094.

94 Doi M, Okano T, Yujnovsky I, Sassone-Corsi P, Fukada Y: Negative control of circadian clock regulator E4BP4 by casein kinase I $\varepsilon$ mediated phosphorylation. Curr Biol 2004; 14:975-980.

95 Kilic E, Hermann DM, Isenmann S, Bähr M: Effects of pinealectomy and melatonin on the retrograde degeneration of retinal ganglion cells in a novel model of intraorbital optic nerve transection in mice. J Pineal Res 2002;32:106-111.

\$6 Tunç AT, Turgut M, Aslan H, Sahin B, Yurtseven ME, Kaplan S: Neonatal pinealectomy induces Purkinje cell loss in the cerebellum of the chick: a stereological study. Brain Res 2006;1067:95-102.

97 Puig B, Ferrer I: Cell death signaling in the cerebellum in Creutzfeldt-Jakob disease. Acta Neuropathol 2001;102:207-215.

-98 Olkowski AA, Wojnarowicz C, Nain S, Ling B, Alcorn JM, Laarveld B: A study on pathogenesis of sudden death syndrome in broiler chickens. Res Vet Sci 2008;85:131-140.

$\checkmark 99$ Matsunaga E, Tauszig-Delamasure S, Monnier PP, Mueller BK, Strittmatter SM, Mehlen P, Chédotal A: RGM and its receptor neogenin regulate neuronal survival. Nat Cell Biol 2004;6:749-755.

100 Lambert JJ, Belelli D, Hill-Venning C, Peters JA: Neurosteroids and $\mathrm{GABA}_{\mathrm{A}}$ receptor function. Trends Pharmacol Sci 1995;16:295-303.

101 Paul SM, Purdy RH: Neuroactive steroids. FASEB J 1992;6:2311-2322.
New Developments in Pineal

Neurosteroids
Neuroendocrinology 2013;98:97-105 DOI: $10.1159 / 000353782$ 